\title{
Septoria quercicola je poškodovala liste rdečega hrasta v drevesnici Štivan
}

\section{Nikica OGRIS*}

Med zdravstvenim pregledom gozdne drevesnice Štivan pri Matenji vasi 3. 7. 2013 smo opazili poškodbe na listih rdečega hrasta (Quercus rubra L.). Na listih so bile rdečkasto rjave pege velikosti $2-5 \mathrm{~mm}$ (slika 1). Pege so imele rob temnejše barve, $v$ osrednjem delu je bila barva svetlejša, ponekod so bile vidne prirastne cone nekroze. V osredju nekroze so bili na spodnji strani lista ugreznjeni v listno tkivo piknidiji (nespolna trosišča), rjavkasti, okrogli, s premerom $50-150 \mu \mathrm{m}$ (slika 2 in 3). V piknidijih so nastajali brezbarvni, nekoliko ukrivljeni konidiji, dimenzij 42-49 × 3,6-4,5 $\mu \mathrm{m}$, največkrat so imeli tri septe, včasih pa tudi 2 ali 4; na mestu septe so bili nekoliko zoženi. Po zgoraj opisanih morfoloških značilnosti smo določili povzročiteljico poškodb listja rdečega hrasta, tj. Septoria quercicola Sacc. Gliva spada v družino Mycosphaerellaceae, njena spolna oblika (teleomorf) še ni znana.

Gliva S. quercicola je razširjena po vsem svetu. V zmernem podnebnem pasu je zelo pogosta. Njeni gostitelji so vse vrste hrastov. Ne povzroča gospodarsko pomembnih poškodb dreves. Ob visoki intenziteti poškodb listov lahko listje prezgodaj odpade. Močno okužena drevesa postajajo manj vitalna in slabše priraščajo. V življenjski nevarnosti so le zelo mlada drevesa, kadar doživijo popolno defoliacijo več let zapored. Ukrepamo le v drevesnicah tako, da liste zaščitimo s fungicidi spomladi, ko so mladi hrastovi listi občutljivi na okužbo.

\section{Možnosti zamenjave}

Pet vrst iz rodu Septoria lahko povzroči podobne simptome, kot smo jih opisali zgoraj: S. querceti Thüm., S. quercicola, S. quercina Desm., S. quercus Thüm., S. dryina Cooke. Za njihovo medsebojno ločevanje je treba odvzeti vzorec in ga mikroskopirati (Tehon, 1937).

\section{Viri}

Brandenburger W. 1985. Parasitische Pilze an Gefäßpflanzen in Europa. Stuttgart, Germany, Gustav Fischer Verlag: 1248 str. Ellis M.B., Ellis J.P. 1985. Microfungi on land plants: and identification handbook. Sydney, Australia, Croom Helm: 818 str.

Maček J. 2008. Gozdna fitopatologija. Ljubljana, Zavod za gozdove Slovenije, Zveza gozdarskih društev Slovenije - Gozdarska založba: 448 str.

Tehon L.R. 1937. Notes on the Parasitic Fungi of Illinois: VI. Mycologia, 29, 4: 434-446

*Gozdarski inštitut Slovenije, Večna pot 2, 1000 Ljubljana nikica.ogris@gozdis.si

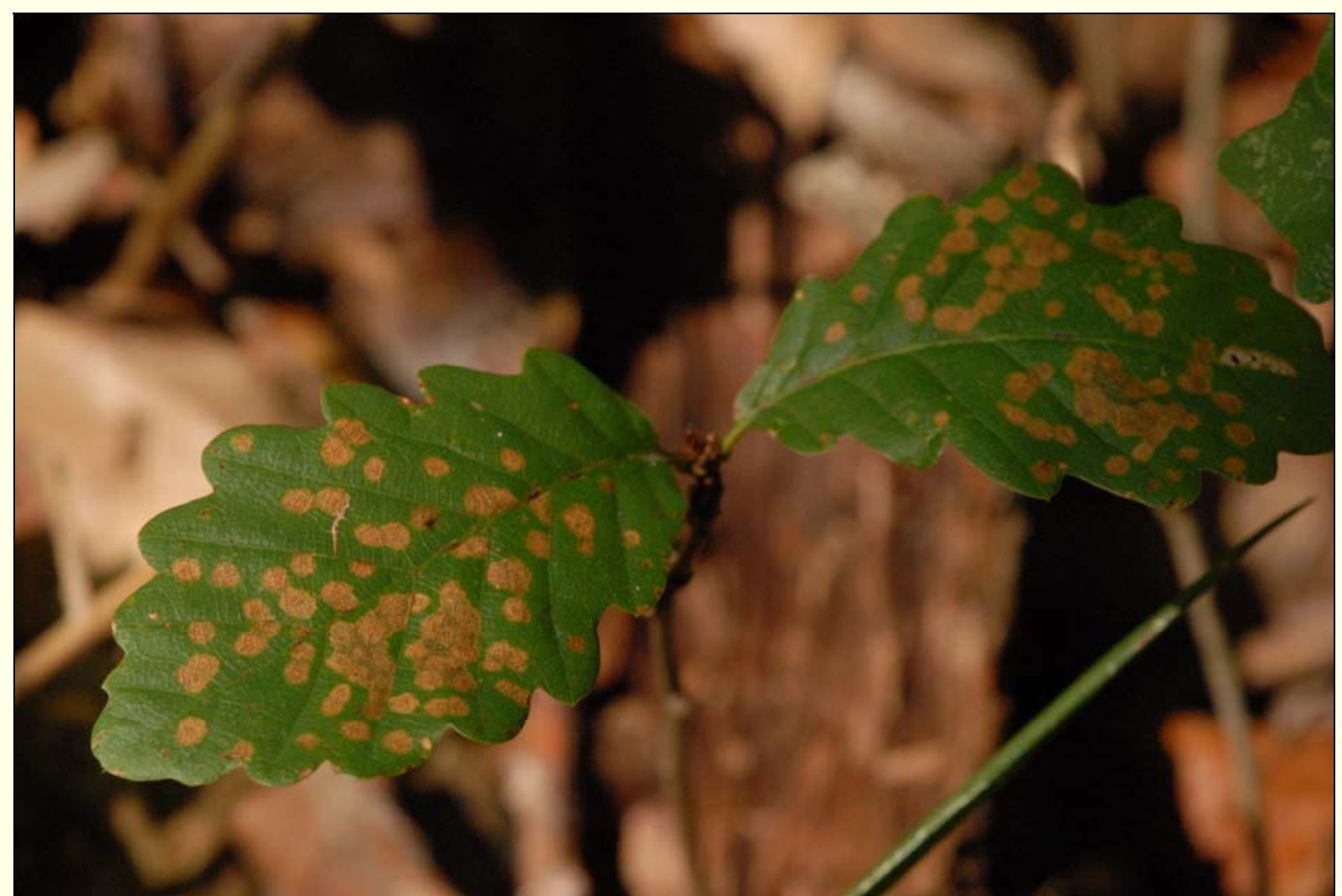

Slika 1: Jakost okužbe zaradi Septoria quercicola je lahko zelo velika (Foto: Dušan Jurc, Rožnik, 21. 9. 2011, graden) 


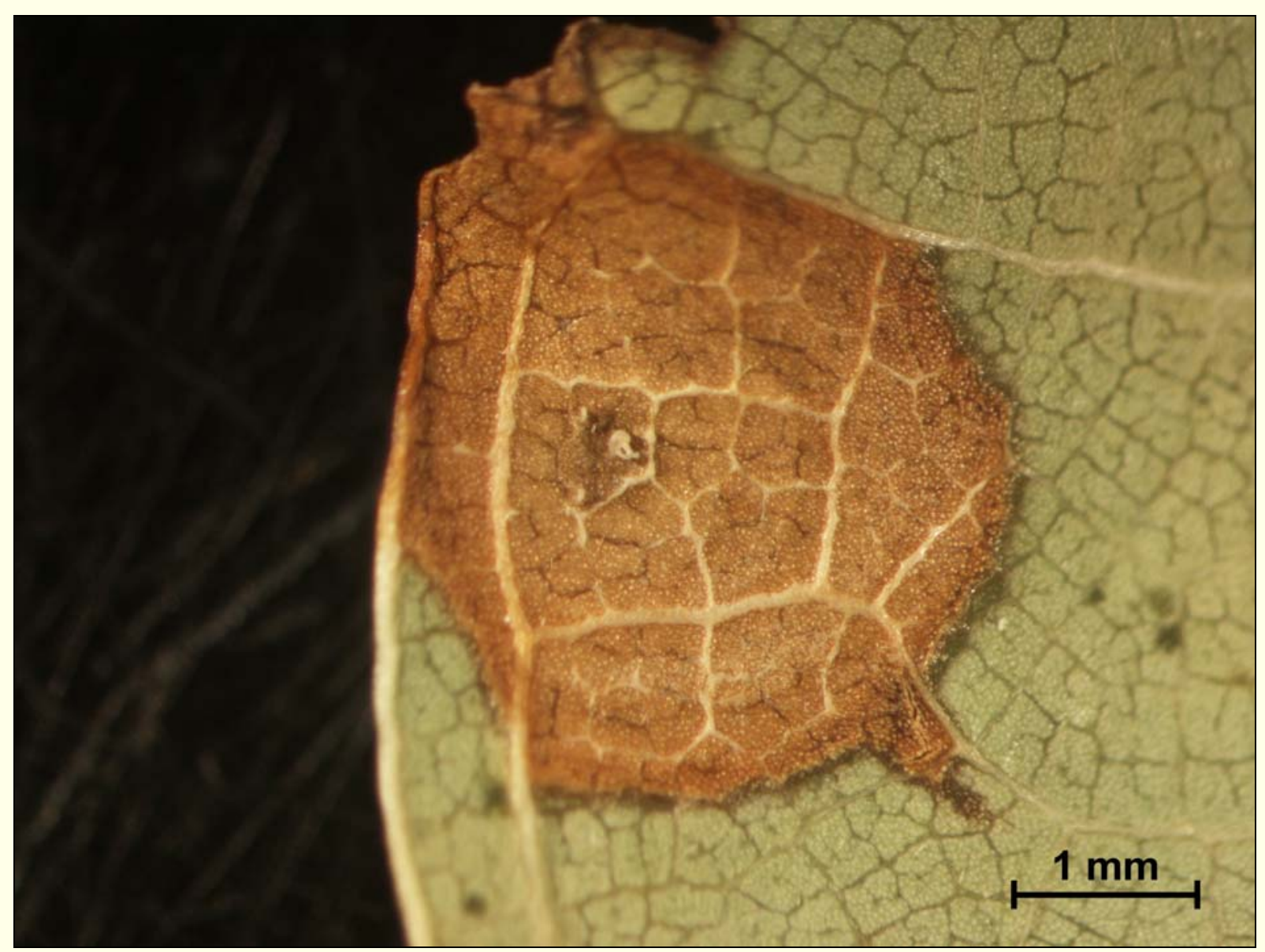

Slika 2: Na spodnji strani lista so v listno tkivo ugreznjeni piknidiji glive Septoria quercicola.

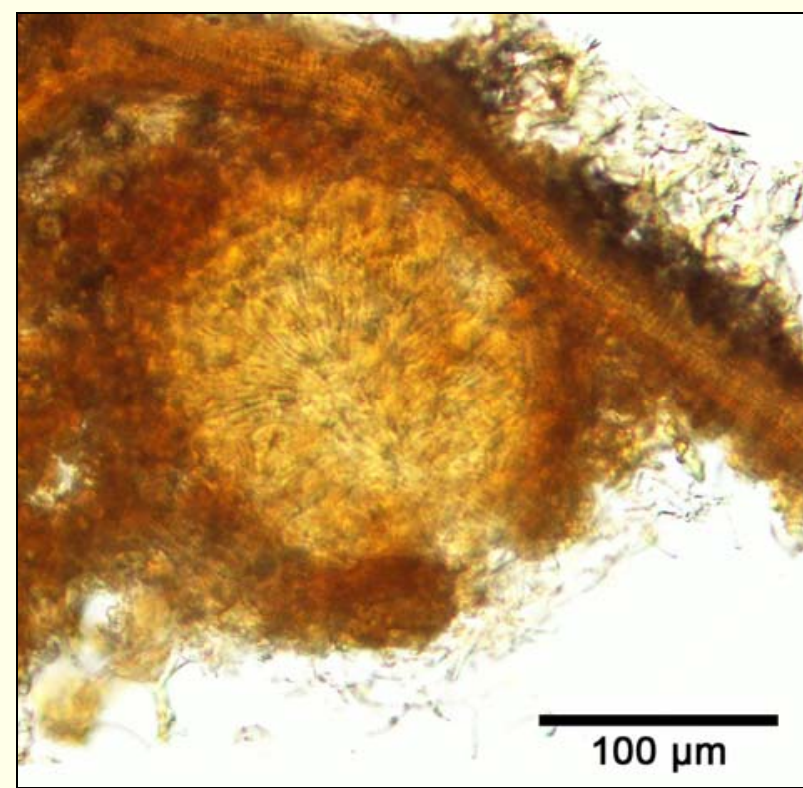

Slika 3: Piknidij Septoria quercicola (Foto: Nikica Ogris)

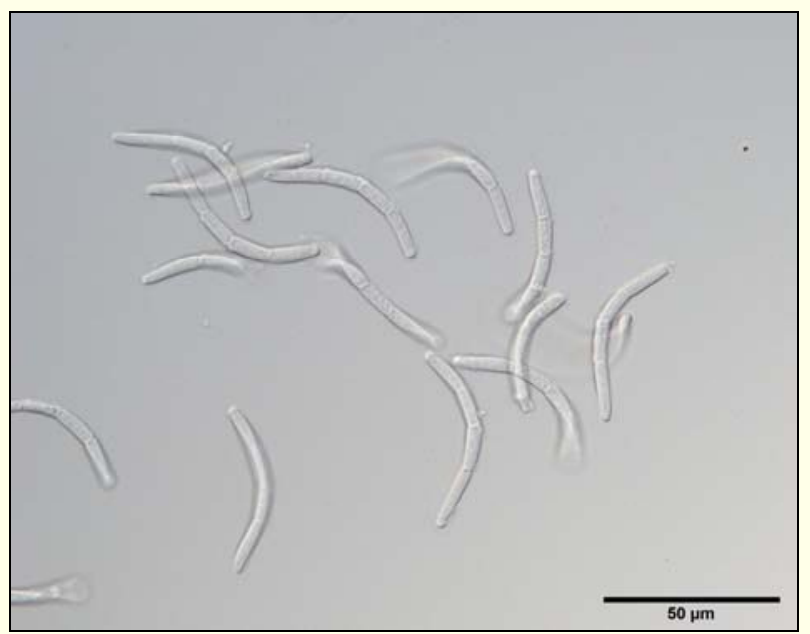

Slika 4: Konidiji Septoria quercicola (Foto: Nikica Ogris) 